\title{
The budget impact of using oral nutritional supplements in older community patients at high risk of malnutrition in England
}

\author{
A. L. Cawood ${ }^{1}$, C. Green ${ }^{2}$ and R. J. Stratton ${ }^{1}$ \\ ${ }^{1}$ Medical Affairs, Nutricia Ltd, Wiltshire BA14 OX, UK and ${ }^{2}$ Global Medical Department, Nutricia Advanced Medical \\ Nutrition Schiphol Airport, NL
}

\begin{abstract}
Although expenditure on nutrition support has been estimated to be less than $2.5 \%$ of the total cost of disease-related malnutrition in the $\mathrm{UK}^{(1)}$, in the current economic climate, there is increasing focus on the expenditure on all forms of prescribable products, including oral nutritional supplements (ONS) (BNF section 9.4.2). Despite increasing evidence to support the use of ready-made ONS ${ }^{(2)}$, there is little understanding of the potential economic effects of their use. Therefore, we developed a model based on an analysis of published literature to investigate the budget impact of using ONS to manage older people in the community in England at high risk of malnutrition using the 'Malnutrition Universal Screening Tool' ('MUST') (http://www.bapen.org.uk).

A budget impact model was developed based on: (1) population data for those aged 65 years or over $(\sim 8$ million people, $16 \%$ of total population) in England ${ }^{(3)}$ and published malnutrition prevalence data ${ }^{(4-6)}$ for those at high risk of malnutrition in the community using 'MUST' (estimated at $\sim 680000$ people); (2) an estimate of the proportion of malnourished older people in the community currently on ONS (9\% of high risk using 'MUST') $v$. those potentially eligible (50\% of those at high risk using 'MUST'); (3) pooled data on clinical outcomes and health-care use (pressure ulcers, infections, antibiotic prescriptions and hospital admissions) from the results of 19 community-based randomised controlled trials ( $n$ 1733) comparing ONS ( $n$ 830) and a control arm ( $n$ 903) (standard care, placebo, dietary counselling and/or normal diet) costed using national tariffs ${ }^{(7,8)}$; (4) costs of health-care professional monitoring ${ }^{(7)}$ and costs of ONS (ONS $b d$ for 8 weeks).

Pooled analysis of data showed reductions in pressure ulcers, infections, antibiotic prescriptions and hospital admissions (by $88,32,56$ and $33 \%$, respectively) with use of ready-made ONS compared to control. The resulting reduction in costs ( $£-88$ million) more than offset the total costs of using ONS in conjunction with health-care professional monitoring (£84 million). Overall, the budget impact showed annual cost savings of $£ 16$ million when using ready-made ONS to manage malnutrition in eligible older people in the community in England.

This budget impact model suggests that the appropriate use of ready-made ONS in eligible older people at high risk of malnutrition in the community is cost effective with the potential for cost savings and a positive budget impact.

1. Elia and Stratton (2008) Calculating the cost of disease-related malnutrition in the UK in (2007). In: Combating Malnutrition: Recommendations for action. BAPEN.

2. NICE (2006) Nutrition Support in Adults CG32. http://www.nice.org.uk/guidance/CG32

3. National Statistics Website (accessed June 2010) (based on mid-2009 data) http://www.statistics.gov.uk/CCI/nugget.asp?ID=6

4. Russell C \& Elia M (2008) Nutrition Screening Survey in the UK in 2007. BAPEN.

5. Russell C \& Elia M (2009) Nutrition Screening Survey in the UK in 2008. BAPEN.

6. Elia M \& Stratton RJ (2005) Nutrition 21, 1100-1106.

7. Curtis L (2009) Unit Costs of Health and Social Care 2009. http://www.pssru.ac.uk

8. British National Formulary (BNF) 2010.
\end{abstract}

